\title{
Fetal ultrasound measurements and associations with postnatal outcomes in infancy and childhood: a systematic review of an emerging literature
}

\author{
Farah Alkandari, ${ }^{1}$ Awaiss Ellahi, ${ }^{1}$ Lorna Aucott, ${ }^{2}$ Graham Devereux, ${ }^{1}$ Steve Turner ${ }^{1}$
}

- Additional material is published online only. To view please visit the journal online (http://dx.doi.org/10.1136/jech2014-204091).

${ }^{1}$ Department of Child Health, University of Aberdeen, Aberdeen, UK

${ }^{2}$ Department of Medical Statistics, University of Aberdeen, Aberdeen, UK

Correspondence to Dr Steve Turner, Child Health, Royal Aberdeen Children's Hospital, Aberdeen, AB25 2ZG, UK;

s.w.turner@abdn.ac.uk

Received 26 February 2014 Revised 20 August 2014 Accepted 22 August 2014 Published Online First 4 September 2014

\section{CrossMark}

To cite: Alkandari $F$,

Ellahi A, Aucott L, et al. J

Epidemiol Community Health 2015:69:41-48.

\section{ABSTRACT}

Background Several hypotheses predict that faltering

fetal growth is an antecedent for common non-

communicable diseases. This is the first systematic review

of an emerging literature linking antenatal fetal

measurements to postnatal outcomes.

Methods Electronic databases (OVID, EMBASE and

Google Scholar) and cohort study websites were

searched in July 2014. Studies were selected which

examined associations between antenatal fetal

ultrasound measurements and postnatal outcomes.

Neonatal outcomes, e.g. premature delivery, were not included.

Results There were 23 papers identified from cohorts in Western countries, including 11 from a single cohort. Four papers reported outcomes in children aged over 6 years. Small, but not large, for gestational age (SGA) was associated with adverse outcomes except for one study where individuals with the lightest or heaviest estimated fetal weight risk were at increased risk for autistic spectrum disorder. The magnitude of associations was modest, e.g. each z score reduction in fetal size was associated with 10-20\% increased risk for delayed development or a $1 \mathrm{~mm} \mathrm{Hg}$ increase in blood pressure. Both growth acceleration and deceleration were both associated with adverse outcomes.

Conclusions There is consistency for antenatal SGA and growth deceleration being associated with adverse outcomes determined in early childhood. Accelerating fetal growth was associated with both advantageous and disadvantageous outcomes, and this is consistent with the concept of predictive adaptive responses where exposure to a postnatal environment which was not anticipated predisposes the fetus to adverse health.

\section{INTRODUCTION}

Historically, before 1990, the human fetus was considered as inhabiting a privileged environment where it was insulated from harm by the maternoplacental unit, ${ }^{1}$ but this paradigm is no longer accepted. Cohort studies with extended follow-up of the offspring of mothers exposed to starvation during pregnancy, such as during the Dutch Famine $^{12}$ and the Leningrad Siege, ${ }^{3}$ have demonstrated how this exposure was associated with both reduced birth weight and increased incidence of non-communicable diseases (NCDs) or their physiological features. ${ }^{4}$ A number of mechanisms have been proposed as explanations for associations between reduced fetal growth, as evidenced by reduced birth weight, and a broad spectrum of adult NCDs for which there is no cure including cardiovascular disease, ${ }^{5}$ type II diabetes, ${ }^{6}$ psychiatric diseases, ${ }^{7}$ chronic renal failure ${ }^{8}$ and polycystic ovarian disease. $^{9}$ These mechanisms include the thrifty phenotype, ${ }^{10}$ the fetal origins hypothesis, ${ }^{5}$ developmental plasticity ${ }^{11}$ and predictive adaptive responses ${ }^{12}$ and collectively fall under the concept of developmental origins of disease ${ }^{4}$ (DOHaD). The thrifty phenotype and fetal origins hypotheses are focused on fetal growth failure and predict that faltering fetal growth will be associated with adverse outcomes. The developmental plasticity and predictive adaptive responses theories are less specific in predicting outcome but maintain that a single individual can achieve a number of phenotypes depending on the developmental milieu and that both fetal growth deceleration and acceleration may be beneficial or harmful to the individual depending on the postnatal environment.

Understanding the developmental mechanisms associated with faltering fetal growth and NCDs will inform antenatal preventative interventions which will ultimately improve the health of the population and reduce burden on healthcare resources. ${ }^{13}$ A major challenge to understanding fetal origins of NCDs in humans is measuring fetal well-being. Fetal anthropometry, as evidenced by ultrasound measurement, has been used as an index of fetal well-being and related to risk for outcomes in childhood. There is now emerging literature relating antenatal fetal measurements to childhood outcomes including asthma, allergy, obesity and hypertension and it is possible to determine whether the literature refutes or supports previous theoretical work. The present systematic review was designed to answer the question "Are there consistent associations between antenatal size (i.e. small for gestational age) and faltering fetal growth and post natal outcomes?" The focus was on postnatal outcomes where $\mathrm{DOHaD}$ may be important and we set out to determine which of the different developmental theories best fitted the summation of the evidence identified.

\section{METHODS}

\section{Search methodology}

The database search was carried out in July 2014 using OVID and also EMBASE and Google Scholar databases. The following terms were used for the search and were identified after reviewing relevant publications already known to the authors (also see online supplementary for search strategy used): 'Child', 'Follow-up/Cohort/Epidemiological/ Cross-sectional/Prospective Studies', 'Fetal growth/ development', 'Infant/Infant New-born' and 
'Humans'. Abstracts were reviewed independently by two researchers (FA and $\mathrm{AE}$ ) and studies which potentially related antenatal fetal outcomes to postnatal outcomes identified. Eligible papers had to include fetal anthropometric ultrasound measurements representative of overall fetal size (i.e. crown rump length (CRL), biparietal diameter (BPD), head circumference (HC), femur length (FL), abdominal circumference (AC) and estimated fetal weight $(\mathrm{EFW}))$ as the predictive variable and postnatal outcomes determined $\geq 1$ week after birth as the outcome. Studies which described outcomes of antenatal fetal congenital anomalies, e.g. echogenic bowel, congenital heart disease, cystic lesions in brain, lung and kidney, were not eligible since these fetal measurements were not representative of overall fetal size. Studies which related fetal measurements to perinatal outcomes (e.g. prematurity, increased/ reduced birth weight and complications of delivery) or maternal exposures during pregnancy (e.g. maternal smoking or ambient air quality) were not eligible since our research question was focused on the relationship between antenatal measurements and postnatal outcomes which were or might be preclinical indices for NCD. Three authors (FA, AE and ST) then agreed on the abstracts where full papers should be accessed. Further papers were identified by searching reference lists of identified papers and also from the websites for three key cohorts where fetal measurements were known to have been linked to postnatal outcomes: Generation R (http:// www.erasmusmc.nl/epi/research/Generation-R/?lang=en),

Southampton Women's Survey (SWS; http://www.leu.soton.ac.uk/ sws/) and Raine Cohort (http://www.rainestudy.org.au/). Outcomes were sought for (1) size for gestational age and (2) fetal growth trajectory (including growth deceleration).

\section{Description of fetal measurements}

In the first trimester (i.e. up to 12 weeks gestation) CRL, BPD and Ac were measured. In the second trimester (i.e. 1327 weeks gestation) and third trimester (i.e. 28 weeks and beyond) HC, FL and BPD and AC were measured; EFW was derived from $\mathrm{HC}, \mathrm{AC}$ and FL measurements.

\section{Quality assessment}

Quality assessment of all the included papers was carried out using a standard tool developed for use in any public health topic area (http://www.ephpp.ca/Tools.html). This process provides the reader with a global score as to the quality of evidence provided plus each study is rated over six domains (selection bias, study design, confounders, blinding, data collection methods and withdrawals and drop outs). Each domain is scored 1-3 and from these scores the global score is derived ( $1=$ strong study design, $2=$ moderate and $3=$ weak). Each paper was scored independently by two of the authors and a final score agreed.

\section{RESULTS}

The OVID search identified 450 study abstracts, 33 full texts were retrieved and 19 of these papers were ultimately included (see figure 1). The EMBASE and Google scholar searches produced 36 and 4074 abstracts, respectively, none of which yielded additional papers. A paper which described associations between antenatal and postnatal echocardiographic outcomes was not included. ${ }^{14}$ Four further papers were identified from previously described cohort websites. Of the 23 papers included in this review, ${ }^{14-36} 11$ arose from the Generation R Cohort, four from SWS, three from the Raine Cohort, two from the Study of Eczema and Asthma To Observe the influence of Nutrition (SEATON) cohort and three from other studies. Only four studies presented results in children aged more than 6 years. ${ }^{16}$ 26-28 All studies were from European, Australian or North American populations. Table 1 describes which fetal measurements were made in the five cohorts whose papers were included. Table 2 gives an overview of associations between SGA and postnatal outcome while table 3 describes associations between changing fetal size and postnatal outcomes. Table E1 on the online data supplementary presents fuller description of the study design and magnitude of the associations reported in individual papers. For each study, outcomes were first related to fetal size for a given gestation and then to fetal growth. Outcomes were categorised into: respiratory, allergy, obesity, neurodevelopmental, autistic spectrum disorders (ASDs), febrile seizures, cardiovascular, renal and bone mineralisation. One of the studies achieved a strong global rating, ${ }^{15} 12$ received a moderate rating (most failed to gain strong rating by not demonstrating how non-participation affected the population demographics) and the remainder were given a weak rating (most failed to gain moderate rating by not demonstrating whether/how confounders such as maternal smoking and socioeconomic status were considered), see online data supplementary table E2. Of the 6 studies which found no evidence of association between small fetal size and postnatal outcome, 4 were of poor quality study design 232635 and 2 of moderate quality. ${ }^{17} 31$ Among the 4 studies which found no association between changing fetal size and outcomes, 3 were of moderate quality design ${ }^{212431}$ and the fourth of poor quality. ${ }^{32}$

\section{Respiratory outcomes}

There were four studies identified including two from the SEATON cohort. In the SEATON cohort, being SGA in the first trimester was associated with higher risk for doctor confirmed asthma and lower forced expiratory volume in $1 \mathrm{~s}\left(\mathrm{FEV}_{1}\right)$ at $5^{15}$ and 10 years of age. ${ }^{16}$ Second trimester SGA (here BPD was the measurement) was associated with higher asthma risk ${ }^{15}$ at 5 and lower $\mathrm{FEV}_{1}$ and forced expiratory flow at $25-75 \%$ of forced vital capacity $\left(\mathrm{FEF}_{25-75}\right)$ at 10 years. ${ }^{16}$ Fetal measurements were not associated with bronchodilator response at 5 years, bronchial hyper-reactivity at 10 years or exhaled nitric oxide at 5 or 10 years. Growth acceleration between the first and second trimesters was associated with lower $\mathrm{FEF}_{25-75}$ at 5 and 10 years but lower asthma risk at 10 years compared with persistent high growth. ${ }^{15}$ Growth acceleration between the first and second trimesters was also associated with lower risk for wheeze at 3 years of age in the SWS ${ }^{18}$; here children were stratified by skin prick positivity, and increasing HC between 11 and 19 weeks was associated with lower risk for non-atopic wheeze. Increasing AC growth between 19 and 34 weeks was also associated with lower risk for atopic wheeze. ${ }^{18}$ In the Generation $\mathrm{R}$ Cohort $^{17}$ there were no associations between fetal measurements or growth and respiratory outcomes at 4 years but postnatal weight gain was positively associated with risk for symptoms, regardless of antenatal size or growth.

\section{Allergy outcomes}

There were four papers identified. In the SEATON cohort, fetal size for a given gestation was not associated with risk for hay fever or eczema at 10 years $^{16}$ (results not presented at 5 years) nor with skin prick reactivity $5^{15}$ or 10 years ${ }^{16}$. When compared with persistent high growth, accelerated fetal growth size during the first and second trimesters was associated with higher eczema risk and decelerating fetal growth with lower hay fever risk at 10 years. ${ }^{16}$ In SWS, ${ }^{18}$ increasing AC growth between weeks 11 and 19 was also associated with higher risk for atopy but increasing $\mathrm{AC}$ growth between 19 and 34 weeks gestation 


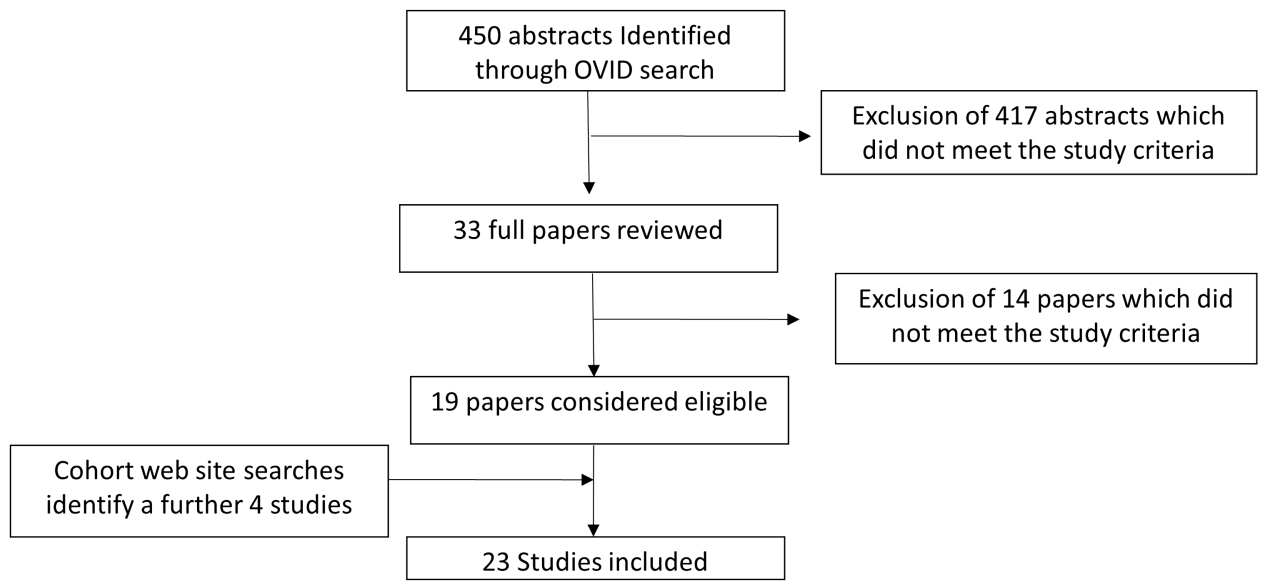

Figure 1 Quorum diagram showing how the papers included in this review were identified.

was associated with decreased risk for atopy in 3-year-olds. ${ }^{18}$ In contrast, in the Generation R Cohort ${ }^{17}$ increasing AC between the second and third trimesters was associated with higher risk for eczema at 4 years.

\section{Obesity}

Obesity outcomes were reported in five studies, four from Generation R. In the Generation R Cohort, absolute measurements of second and third trimester EFW were not related to fat mass at age 6 months (calculated by dual-energy X-ray absorptiometry, DEXA), ${ }^{20}$ but a relative increase in EFW z score of $>0.67$ was associated with higher fat mass. In a second paper from Generation R, SGA for third (but not second) trimester EFW was associated with an increase of borderline significance in ultrasound-determined abdominal fat deposits at age 2 years ${ }^{21}$; the change in EFW between the second and third trimesters was not associated with abdominal fat measurements. ${ }^{21}$ In the third paper, first trimester CRL and second and third trimester FL and EFW were linked to peak velocities in height, weight and body mass index (BMI) up to 4 years of age. ${ }^{22}$ There was no association between first trimester CRL and outcomes. There were positive associations between second (but

Table 1 Details of the five cohorts which have linked antenatal fetal measurements to postnatal outcomes

\begin{tabular}{|c|c|c|c|c|c|c|}
\hline Cohort & Country & $\begin{array}{l}\text { Years of } \\
\text { recruitment }\end{array}$ & Number recruited & $\begin{array}{l}\text { Fetal } \\
\text { measurements } \\
\text { available }\end{array}$ & $\begin{array}{l}\text { Rationale for recruiting } \\
\text { cohort }\end{array}$ & $\begin{array}{l}\text { Inclusion and exclusion } \\
\text { criteria }\end{array}$ \\
\hline Generation $\mathrm{R}^{42}$ & The Netherlands & $2002-2006$ & $\begin{array}{l}9778 \text { mothers and details } \\
\text { from } 5125 \text { offspring } \\
\text { including more detailed } \\
\text { assessment in } \leq 1232\end{array}$ & $\begin{array}{l}\text { T1: CRL (used for } \\
\text { dating) } \\
\text { T2+3: BPD, HC, AC } \\
\text { FL, EFW, transverse } \\
\text { cerebellar diameter }\end{array}$ & $\begin{array}{l}\text { To identify early environmental } \\
\text { and genetic causes of normal } \\
\text { and abnormal growth, } \\
\text { development and health from } \\
\text { fetal life until young adulthood }\end{array}$ & $\begin{array}{l}\text { Delivery date April } 2002- \\
\text { January } 2006 \text {. Recruitment } \\
\text { any time during pregnancy } \\
\text { (ideally }<18 \text { weeks). } \\
\text { Living within Rotterdam } \\
\text { area. No exclusion criteria } \\
\text { stated }\end{array}$ \\
\hline $\begin{array}{l}\text { Southampton } \\
\text { Women's } \\
\text { Survey }^{43}\end{array}$ & UK & 1998-2002 & $\begin{array}{l}12579 \text { women ( } 75 \% \text { of } \\
\text { all women approached) } \\
\text { of whom } 2567 \text { became } \\
\text { pregnant and delivered } \\
\text { live born infant by } 2005\end{array}$ & $\begin{array}{l}\text { Weeks } 11,19 \text { and } \\
\text { 34: FL, AC }\end{array}$ & $\begin{array}{l}\text { To learn more about the dietary } \\
\text { and lifestyle factors that } \\
\text { influence the health of women } \\
\text { and their children }\end{array}$ & $\begin{array}{l}\text { Women aged } 20-34 \text { years } \\
\text { recruited between } 1998 \text { and } \\
2002 \text {. Infant born } \\
<37 \text { weeks gestation were } \\
\text { excluded }\end{array}$ \\
\hline Raine Cohort ${ }^{44}$ & Australia & 1989-1991 & 2876 & $\begin{array}{l}\text { Weeks } 18,24,28,34 \\
\text { and } 38 \text { (in } 1415^{*} \text { ): } \\
\mathrm{AC}, \mathrm{HC} \text { and } \mathrm{FL}\end{array}$ & $\begin{array}{l}\text { To determine whether use of } \\
\text { multiple ultrasound assessments } \\
\text { improved pregnancy outcomes }\end{array}$ & $\begin{array}{l}\text { Mothers } 16-20 \text { weeks } \\
\text { pregnant. Fluent in English } \\
\text { and expected to deliver in } \\
\text { the recruiting hospital }\end{array}$ \\
\hline SEATON study ${ }^{45}$ & UK & 1997-1999 & $\begin{array}{l}2000 \text { mothers (of } 2690 \\
\text { invited to take part) who } \\
\text { delivered } 1924 \text { live born } \\
\text { singleton infants }\end{array}$ & $\begin{array}{l}\text { T1 CRL, T2 BPD and } \\
\text { FL no antenatal T3 } \\
\text { measurements }\end{array}$ & $\begin{array}{l}\text { To detect associations between } \\
\text { maternal diet during pregnancy } \\
\text { and childhood asthma and } \\
\text { eczema }\end{array}$ & $\begin{array}{l}\text { Mother } 10-12 \text { weeks } \\
\text { pregnant. Other exclusion } \\
\text { and inclusion criteria not } \\
\text { described }\end{array}$ \\
\hline $\begin{array}{l}\text { Project Viva }{ }^{46} \\
\text { http://dacp.org/ } \\
\text { viva/index.html }\end{array}$ & USA & 1999-2002 & $\begin{array}{l}2671 \text { mothers ( } 64 \% \text { of } \\
\text { eligible) of whom scan } \\
\text { details were used in } 772 \\
\text { and of these } 438 \text { were } \\
\text { followed up at } 3 \text { years }\end{array}$ & $\begin{array}{l}\text { T2 (18 weeks) BPD, } \\
\mathrm{FL}, \mathrm{AC} \text { and } \mathrm{EFW}\end{array}$ & $\begin{array}{l}\text { To find ways to improve the } \\
\text { health of mothers and their } \\
\text { children by looking at the effects } \\
\text { of mother's diet as well as other } \\
\text { factors during pregnancy and } \\
\text { after birth }\end{array}$ & $\begin{array}{l}\text { Mothers recruited after } \\
\text { initial clinical prenatal visit } \\
\text { ( } \leq 22 \text { weeks gestation). } \\
\text { Exclusion criteria included } \\
\text { multiple pregnancy, not } \\
\text { fluent in English }\end{array}$ \\
\hline
\end{tabular}

T1, 2 and 3 are first, second and third trimesters.

*The Raine Cohort was designed to determine whether regular antenatal ultrasounds were associated with higher risk of harm to the fetus; mothers were randomised to have either one or five assessments.

$\mathrm{AC}$, abdominal circumference; $\mathrm{BPD}$, biparietal diameter; $\mathrm{CRL}$, crown rump length; EFW, estimated fetal weight (derived from $\mathrm{HC}$, $\mathrm{FL}$ and $\mathrm{AC}$ ); FL, femur length; $\mathrm{HC}$, head circumference; SEATON, Study of Eczema and Asthma To Observe the influence of Nutrition. 
Table 2 Summary of associations between being SGA in the first, second and third trimester and outcomes in postnatal life

\begin{tabular}{|c|c|c|c|c|}
\hline \multirow[b]{2}{*}{ Outcome } & \multirow[b]{2}{*}{ Cohort } & \multicolumn{3}{|c|}{ Associations with being small for gestational age } \\
\hline & & $\begin{array}{l}\text { First trimester } \\
\text { (approximately } \\
10 \text { weeks) }\end{array}$ & $\begin{array}{l}\text { Second trimester } \\
\text { (approximately } 20 \text { weeks) }\end{array}$ & $\begin{array}{l}\text { Third trimester } \\
\text { (approximately } 30 \text { weeks) }\end{array}$ \\
\hline \multirow[t]{3}{*}{ Respiratory } & SEATON ${ }^{15} 16$ & $\begin{array}{l}\text { Higher risk for asthma at } \\
10 \text { years (CRL) } \\
\text { Lower lung function at } \\
10 \text { years (CRL) }\end{array}$ & $\begin{array}{l}\text { Higher risk for asthma at } 10 \text { years (BPD) } \\
\text { Lower lung function at } 10 \text { years (BPD) }\end{array}$ & Scan not done \\
\hline & SWS $^{18}$ & \multicolumn{3}{|c|}{ Outcomes with SGA not reported } \\
\hline & Generation $\mathrm{R}^{17}$ & $\begin{array}{l}\text { No association with } \\
\text { symptoms at } 4 \text { years }\end{array}$ & \multicolumn{2}{|l|}{ Outcomes with SGA not reported } \\
\hline Allergy & $\begin{array}{l}\text { SEATON }{ }^{1516} \\
\text { SWS }^{18} \\
\text { Generation } R^{17}\end{array}$ & \multicolumn{3}{|c|}{$\begin{array}{l}\text { No associations apparent between SGA and eczema, hay fever, skin prick reactivity or exhaled nitric oxide } \\
\text { Outcomes with SGA not reported } \\
\text { Outcomes with SGA not reported }\end{array}$} \\
\hline \multirow[t]{2}{*}{ Obesity } & Generation $\mathrm{R}^{20-22}$ & Not associated with PGV & $\begin{array}{l}\text { No relationship with EFW and fat mass at } \\
6 \text { months or AFM at } 2 \text { years. EFW associated } \\
\text { with lower weight PGV and body mass index at } \\
\text { adiposity peak. FL inversely associated with } \\
\text { height PGV }\end{array}$ & $\begin{array}{l}\text { No relationship with EFW and fat mass at } \\
6 \text { months but borderline association with AFM } \\
\text { at } 2 \text { years and body mass index at adiposity } \\
\text { peak }\end{array}$ \\
\hline & Project Viva ${ }^{19}$ & Scan not done & $\begin{array}{l}\text { Reduced EFW associated with lower body mass } \\
\text { index and obesity at } 3 \text { years }\end{array}$ & Scan not done \\
\hline Plasma lipids & Generation $\mathrm{R}^{36}$ & $\begin{array}{l}\text { SGA associated with } \\
\text { increased plasma } \\
\text { cholesterol at six years of } \\
\text { age }\end{array}$ & Outcomes with SGA not reported & Outcomes with SGA not reported \\
\hline \multirow[t]{2}{*}{ Neurodevelopment } & Generation $\mathrm{R}^{2425}$ & $\begin{array}{l}\text { Higher risk for delayed fine } \\
\text { motor development at } \\
12 \text { months (HC) }\end{array}$ & $\begin{array}{l}\text { SGA AC, EFW and AC:HC (not HC) associated } \\
\text { with neuromotor developmental delay at 9- } \\
15 \text { weeks. SGA HC associated with delayed fine } \\
\text { motor development at } 12 \text { months }\end{array}$ & $\begin{array}{l}\text { SGA AC, EFW and AC:HC (not HC) associated } \\
\text { with neuromotor developmental delay at 9- } \\
15 \text { weeks. SGA HC associated with global } \\
\text { developmental delays at } 12 \text { months }\end{array}$ \\
\hline & Raine $^{23}$ & Scan not done & $\begin{array}{l}\text { No association with specific language } \\
\text { impairment at } 10 \text { years }\end{array}$ & Association not reported \\
\hline \multirow[t]{3}{*}{ Autism } & Raine $^{27}$ & Scan not done & No association with $\mathrm{HC}$ and autism at 16 years & Association not reported \\
\hline & Hobbs et $a l^{26}$ & Scan not done & $\begin{array}{l}\text { No association with BPD, AC or FL and autism } \\
\text { (mean age } 7 \text { years) }\end{array}$ & Scan not done \\
\hline & Abel et $a l^{28}$ & Scan not done & $\begin{array}{l}\text { Group with lowest (and also highest) EFW at } \\
\text { highest risk for autism by } 17 \text { years }\end{array}$ & Scan not done \\
\hline Febrile convulsion & Generation $\mathrm{R}^{29}$ & Association not reported & $\begin{array}{l}\text { SGA transverse cerebellar diameter associated } \\
\text { with higher risk }\end{array}$ & $\begin{array}{l}\text { SGA for transverse cerebellar diameter, EFW, } \\
\mathrm{AC} \text { and } \mathrm{FL} \text { (not } \mathrm{HC} \text { ) associated with higher } \\
\text { risk }\end{array}$ \\
\hline \multirow[t]{3}{*}{ Blood pressure } & Raine $^{30}$ & Scan not done & $\begin{array}{l}\text { SGA for FL (not AC or HC) at } 24 \text { weeks (not 18) } \\
\text { associated with higher SBP at } 6 \text { years }\end{array}$ & $\begin{array}{l}\text { SGA for FL (not AC or HC) throughout } \\
\text { associated with higher SBP at } 6 \text { years }\end{array}$ \\
\hline & Generation $\mathrm{R}^{31}$ & Association not reported & $\begin{array}{l}\text { No association between } \mathrm{FL}, \mathrm{AC}, \mathrm{HC} \text { or EFW and } \\
\text { SBP at } 2 \text { years }\end{array}$ & SGA FL associated with higher SBP at 2 years \\
\hline & Project Viva ${ }^{19}$ & Scan not done & $\begin{array}{l}\text { No association between EFW and SBP at } \\
3 \text { years }\end{array}$ & Scan not done \\
\hline Renal & Generation $\mathrm{R}^{32}$ & Association not reported & $\begin{array}{l}\text { No association between } \mathrm{HC} \text { and } \mathrm{AC} \text { and kidney } \\
\text { volume at } 2 \text { years }\end{array}$ & $\begin{array}{l}\text { No association between } \mathrm{HC} \text { and } \mathrm{AC} \text { and } \\
\text { kidney volume at } 2 \text { years }\end{array}$ \\
\hline Bone & SWS $^{33} 34$ & Outcomes with SGA not repo & rted & \\
\hline mineralisation & Generation $\mathrm{R}^{35}$ & Association not reported & $\begin{array}{l}\text { SGA for EFW associated with lower bone } \\
\text { mineral density and content at } 6 \text { months }\end{array}$ & $\begin{array}{l}\text { SGA for EFW associated with lower bone } \\
\text { mineral density and content at } 6 \text { months }\end{array}$ \\
\hline
\end{tabular}

not third) trimester EFW and peak weight velocity and FL and peak height velocity. Second and third trimester EFW and relative growth between these times were all positively related to BMI at adiposity peak. In the final paper from the Generation $\mathrm{R}$ Cohort, first trimester size was related to total body fat at a median age of 6 years and each increase in $\mathrm{z}$ score in CRL was associated with a $0.3 \%$ reduction in total body fat $(95 \% \mathrm{CI}$ $0.03 \%$ to $0.57 \%) .{ }^{36}$ In the Project Viva Cohort, ${ }^{19}$ individuals in the highest quartile for EFW had higher BMI z score at 3 years and were at higher risk for obesity (defined as $\geq 95$ th centile) when compared with the lowest quartile. ${ }^{19}$ Compared with individuals in the lowest EFW and birthweight quartiles, those in the highest EFW and birthweight quartiles had higher BMI at 3 years of age. There were no associations between EFW and birth weight and skinfold thickness at 3 years of age, i.e. an index of adiposity. ${ }^{19}$

\section{Plasma lipid outcomes}

In a recent paper from the Generation $\mathrm{R}$ Cohort ${ }^{36}$ each $\mathrm{z}$ score increase in CRL was linked to a mean reduction of $0.05 \mathrm{mmol} / \mathrm{L}$ cholesterol (95\% CI 0 to 0.10 ) in 6-year-olds. There was also a trend which approached significance for an inverse relationship between CRL and plasma low density lipoprotein, but no association was apparent for triglycerides. 
Table 3 Summary of adverse outcomes associated with increasing or decreasing growth in fetal measurements during the first or second half of pregnancy

\begin{tabular}{|c|c|}
\hline Growth before 20 weeks gestation (fetal outcome measured) & Antenatal growth after 20 weeks gestation (fetal outcome measured) \\
\hline \multicolumn{2}{|l|}{ Accelerating growth } \\
\hline $\begin{array}{l}\text { Lower spirometry at } 5^{15} \text { and } 10 \text { years } \\
\text { Higher asthma risk at } 10 \text { years }{ }^{16}(\mathrm{CRL} \text { and } \mathrm{BPD}) \\
\text { Higher eczema risk at } 10 \text { years }{ }^{16} \text { (CRL and BPD) } \\
\text { Higher atopy at } 3 \text { years }{ }^{18}(\mathrm{AC}) \\
\text { Higher non-atopic wheeze at } 3 \text { years }{ }^{18}(\mathrm{HC})\end{array}$ & $\begin{array}{l}\text { Higher systolic blood pressure at } 3 \text { years }{ }^{19} \text { (FL) } \\
\text { Lower spirometry at } 10 \text { years }{ }^{16} \text { (BPD and birth weight) } \\
\text { Higher asthma risk at } 10 \text { years }{ }^{16} \text { (BPD and birth weight) } \\
\text { Lower hay fever risk at } 10 \text { years }{ }^{16} \text { (BPD and birth weight)* } \\
\text { Higher eczema risk at } 4 \text { years }{ }^{17} \text { (AC) } \\
\text { Higher fat mass at } 6 \text { months }{ }^{20} \text { (EFW) } \\
\text { Higher body mass index at adiposity peak }{ }^{22} \text { (EFW) }\end{array}$ \\
\hline \multicolumn{2}{|l|}{ Decelerating growth } \\
\hline $\begin{array}{l}\text { Lower spirometry (FVC) at } 10 \text { years }^{16} \text { (CRL and BPD) } \\
\text { Lower risk for hay fever at } 10 \text { years }^{16}(\mathrm{CRL} \text { and BPD) } \\
\text { Higher risk for delay in fine motor development at } 12 \text { months }{ }^{25}(\mathrm{HC}) \\
\left.\text { Lower bone mineral content at birth and } 4 \text { years }{ }^{34} \text { (FL and } \mathrm{AC}\right) \\
\text { Lower femoral neck section modulus (FL) }\end{array}$ & $\begin{array}{l}\text { Higher risk for several developmental outcomes }{ }^{25}(\mathrm{HC}) \\
\text { Higher risk for febrile convulsions }{ }^{29} \text { (EFW) } \\
\text { Lower bone mineral density at } 6 \text { months }^{35} \text { (EFW) } \\
\text { Lower bone mineral content at } 4 \text { years }{ }^{33} \text { (FL) } \\
\text { Higher systolic blood pressure at } 3^{19} \text { and } 6 \text { years }{ }^{30} \text { (FL) } \\
\text { Higher risk for atopy at } 3 \text { years }{ }^{18}(\mathrm{AC}) \\
\text { Higher risk for atopic wheeze at } 3 \text { years }{ }^{18}(\mathrm{AC}) \\
\text { Lower femoral neck section modulus (FL) }^{37}\end{array}$ \\
\hline
\end{tabular}

\section{Neurodevelopment}

There were three studies to consider neurodevelopment. One Generation R Cohort paper described associations between SGA for second and third trimester AC, EFW and ratio of AC:HC (but not $\mathrm{HC}$ per se) and higher risk for being in the lowest tertile for Touwen's Neurodevelopmental Examination at 915 weeks of age. ${ }^{24} \mathrm{~A}$ second Generation R Cohort publication related SGA fetal HC measurements in early, mid and late pregnancy to increased risk for delayed social development at 12 months; SGA HC in late pregnancy was also associated with increased risk for delays in self-help and fine motor skills. Reduced relative size in HC between early and mid pregnancy was associated with higher risk for delayed fine motor development and SGA HC growth in later pregnancy with higher risk for delayed self-help abilities, gross and fine motor and language development at 12 months. ${ }^{25} \mathrm{~A}$ case-control study from the Raine Cohort related FL and HC at 18 weeks and HC at delivery to specific language impairment, ${ }^{23}$ and there were no differences in fetal measurements between the 30 cases and 30 controls. The prevalence of microcephaly (i.e. HC at birth < $-1.67 \mathrm{z}$ score) was higher among cases (40\%) compared with controls $(10 \%) .^{23}$

\section{Autistic spectrum disorders}

There were three case-control studies. A study from the Raine Cohort found no difference in HC at 18 weeks gestation and birth between 14 cases with ASD and 56 matched controls. ${ }^{27} \mathrm{~A}$ study from America ${ }^{26}$ also found no difference in second trimester BPD, AC and FL between 45 cases and 222 controls. In a post hoc analysis, cases were subcategorised as multiplex autism (i.e. autism occurring in association with schizophrenic symptoms, $n=8)$ or simplex autism $(n=33)$; multiplex autism was associated with SGA AC compared with simplex autism and also with controls. ${ }^{26}$ A third study from Sweden compared second trimester EFW between 4283 children with ASD and 36588 controls. $^{28}$ ASD risk was higher for the smallest and largest EFW, i.e. both small and large for gestational age. When individuals were subcategorised as ASD with or without intellectual disability, the associations with EFW were similar.

\section{Febrile seizures}

The Generation R Cohort team related SGA second and third trimester fetal transverse cerebellar diameter to risk for febrile seizures by 2 years of age. ${ }^{29}$ There were 67 cases among the 3372 children studied. Individuals in the lowest tertile of third trimester EFW, AC and FL (but not HC) measurements were also at higher risk for febrile seizures compared with the highest tertile. Cases had EFW similar to controls at 16 weeks gestation, but by 34 weeks gestation, EFW was $-0.4 \mathrm{z}$ scores relatively lower for cases suggesting IUGR rather than SGA was important.

\section{Cardiovascular outcomes}

Four reports considered cardiovascular outcomes. A study from the Raine Cohort related FL, AC and HC measured between 18 and 38 weeks gestation to systolic blood pressure (SBP) at age 6 years in 707 individuals $^{30}$ and observed an inverse association between FL and SBP. A similar finding was seen in the Generation R Cohort where SGA FL at 30 (but not 20) weeks gestation was associated with increased SBP at age 2 years. ${ }^{31} \mathrm{~A}$ second Generation $\mathrm{R}$ study reported a mean reduction in diastolic (but not systolic) blood pressure at 6 years of age of $0.43 \mathrm{~mm} \mathrm{Hg}(0.01,0.84)$ for each $\mathrm{z}$ score increase in first trimester CRL, but this association was not significant when the child's weight was considered. ${ }^{36}$ In the Project Viva Cohort, ${ }^{19}$ relative to individuals in the lowest quartiles for both EFW and birth weight, elevated SBP at 3 years was present among those who were (1) in the highest EFW quartile and second lowest birthweight quartile (2) in the second lowest quartile for both and (3) in the second lowest EFW quartile and second highest birthweight quartile.

\section{Renal outcomes}

In the one paper identified, third (but not second) trimester HC and $\mathrm{AC}$ were positively associated with kidney volume at the age of 2 years. ${ }^{32}$ There was no association between growth in $\mathrm{HC}$ and $\mathrm{AC}$ between the second and third trimesters and kidney volume. $^{32}$ 


\section{Bone mineralisation}

There were four studies identified. In the first of three studies from the SWS, FL measurements at 19 and 34 weeks and growth between these gestations were positively associated with bone mineral content (BMC) and skeletal size (expressed as bone area) in 4 -year-olds ${ }^{33}$; bone outcomes were determined by whole-body DEXA scan. There were less convincing positive associations between AC and bone mineralisation. Femoral neck section modulus, an index of bending strength and relevant to fractures in the elderly, was determined in 493 6-year-olds in SWS, and increasing FL growth between 19 and 34 weeks (and to a lesser degree between 11 and 19 weeks) was positively associated with this outcome. ${ }^{37}$ In the second study, growth in FL and $\mathrm{AC}$ between the 11th and 19th weeks of pregnancy was positively associated with bone area and BMC at birth and 4 years of age. ${ }^{34}$ In the Generation R Study, ${ }^{35}$ second and third trimester EFW were positively associated with bone mineral density (BMD) and BMC in 6-month-olds; some associations were only present for either lumbar spine only or total body BMD and BMC. Change in EFW between 20 and 30 weeks, but not between 30 weeks and term, was also positively associated with BMD for total body.

\section{DISCUSSION}

This is the first systematic review of the literature relating antenatal fetal size and growth to postnatal outcomes. We considered a broad spectrum of postnatal outcomes since some organs pass through important developmental stages at the same gestation and an antenatal exposure at a given time might affect more than one organ. Equally, different organs develop at different gestations and serial fetal ultrasound measurements can give insight into the developmental origins of different health outcomes. The first main finding was that when associations were present, it was small for a given gestational age (and not large) that was linked to adverse outcomes with the exception of one study which found higher risk for ASD among the smallest and largest second trimester fetuses. ${ }^{28}$ The second notable finding was that growth deceleration was associated with some unfavourable outcomes, although there were some inconsistencies between studies. The final important finding was that in utero growth acceleration was associated with adverse and beneficial outcomes (e.g. higher risk for asthma, obesity and atopy but also higher BMD, table 3). The magnitude of associations between fetal measurements and outcomes, when present, was generally modest for an individual, but these associations may be relevant to public health where small changes in risk may lead to large absolute number of individuals with incurable outcomes such as coronary artery disease, type II diabetes and asthma. Our conclusions are based on studies from Europe, North America and Australia; this adds a limitation that the results may not be generalisable to other populations where different genetic, environmental and socioeconomic influences may be present. We point out that causation cannot be implied from the associations we describe from the observational studies identified. The cohort members are still young; some of the associations described may resolve over time and it will be many years before follow-up will be able to link fetal measurements to outcomes such as cardiovascular disease ${ }^{5}$ and type II diabetes. ${ }^{6}$

Most studies found SGA to be associated with a higher risk for 'adverse' outcomes, and included birth weight and postnatal measurements in the analyses indicating that the 'adverse outcomes' were not simply small fetuses becoming small infants and children. Inclusion of birth weight as a confounder does determine whether antenatal or neonatal measurement is more relevant to the outcome. Inclusion of birth weight might be a case of over adjustment since this birth weight is on any causal pathway between fetal measurements and postnatal outcome, and therefore unlikely to be a confounder. Moreover adjustment for birth weight may inadvertently adjust for a mediator/exposure which affects fetal growth in later pregnancy.

Developmental pauses at critical stages of development might explain these associations, e.g. the association between small for gestation and lower lung function was apparent from the first trimester ${ }^{16}$ suggesting a problem in development occurring in very early pregnancy whereas associations with higher blood pressure were more apparent at 30 weeks gestation than at 20 weeks. $^{30} 31$ During the embryonic and fetal periods, organs develop according to different timetables; e.g. in the lungs, airway division occurs by 16 weeks gestation, ${ }^{38}$ whereas in the kidneys, glomerulogenesis occurs between 7 and 35 weeks gestation. $^{39}$ In this context, a transient exposure before 16 weeks might lead to a life-long aberration in airway function but not adversely affect renal function, and the fetus will achieve a normal/near normal birth weight.

There was some consistency between studies for associations between change in fetal size and outcomes, e.g. (1) accelerated growth during early pregnancy associated with higher risk for eczema $^{16}$ and atopy ${ }^{18}$ (2) accelerated growth during later pregnancy associated with increased fat mass, ${ }^{20} \mathrm{BMI}^{22}$ and BMD. ${ }^{33} 35$ There were also some apparent inconsistent associations between studies, e.g. (1) accelerated growth during late pregnancy and higher risk for eczema ${ }^{17}$ but also lower risk for atopy $^{18}$ and hay fever ${ }^{16}$ (2) accelerating ${ }^{19}$ and decelerating ${ }^{19}$ growth during later pregnancy associated with higher SBP or not at all. ${ }^{31}$ These different outcomes may reflect differences in ages at postnatal assessment, different methodologies used to measure outcomes and differences between study populations. These different outcomes might also reflect genuine differences in determinants of antenatal growth in different populations.

The 'fetal origins' hypothesis proposed that faltering growth during mid gestation was associated with higher risk for cardiovascular disease, and we found evidence of faltering fetal growth being associated with higher blood pressure (table 3) and also with other unfavourable outcomes including lower lung function and developmental delay. We also found evidence for increasing growth during early and late pregnancy being associated with higher risk for adverse outcomes in young children including lower lung function, increased asthma and adiposity (table 3). Associations between relative acceleration and deceleration in growth and 'advantageous' and 'disadvantageous' outcomes are not consistent with the fetal origins hypothesis but are in keeping with the predictive adaptive response hypothesis ${ }^{12}$ where fetal growth anticipates the postnatal environment, and inappropriate (positive or negative) fetal growth may be disadvantageous. The relationship between fetal growth and postnatal outcomes may be modified by postnatal growth trajectories, as was found in some studies included in this review. ${ }^{17} 20$ Large cohorts with detailed follow-up and advanced statistical approaches are required to understand the complex relationship between antenatal growth and postnatal morbidity.

There are a number of limitations to this review. First, there was considerable heterogeneity between study designs, and meta-analysis of data was not possible; furthermore, outcomes measured within studies sometimes varied as the study participant became older, e.g. obesity and neurodevelopmental outcomes, and this limits direct comparison of results from the same cohort. Second, gestational age certainty is crucial to the 
accurate interpretation of fetal measurements ${ }^{40}$ and there is inevitable inaccuracy regardless of whether date of last menstrual period or first trimester fetal measurement is used (or combination of these); however, this inaccuracy is not likely to alter the direction of any associations between fetal size and outcome within a population but is likely to reduce the true magnitude of any association. A third factor to consider is that fetal measurements may not be an accurate index of fetal wellbeing, although the evidence from this review does support the role of fetal measurements as a surrogate for fetal well-being. Statistical points to note are that false-positive results with borderline $\mathrm{p}$ values may have arisen due to multiple testing within studies and also due to post hoc analyses. Fourth, our quality control found that only one study had strong design; although blinding and data collection methods were strong, details were missing for how representative cohorts were of the general population, how incomplete participation at post natal follow-up might bias the population studies and the confounders adjusted for. Perhaps most importantly, there were no intervention studies included and causation can only be determined from such studies and not from observational studies such as we describe here. Nutritional interventions aimed preventing impaired fetal growth, but where antenatal fetal measurements were not made, have met with limited success ${ }^{41}$ and might offer a mechanism to alter antenatal growth.

In conclusion, this review of the literature has identified evidence that small fetal size and changes in fetal growth trajectory may be important to postnatal outcomes. These associations do not prove causation but do suggest that antenatal interventions might be one option of preventing NCDs in adulthood. The associations reported here require replication in non-Western populations to confirm worldwide generalisability. Future research might look at intervention strategies aimed at preventing SGA and growth failure but avoid stimulating fetal growth acceleration since this may lead to unwanted outcomes.

\section{What is already known on this subject}

- Poor fetal growth (as evidenced by low birth weight) is associated with adverse outcomes in childhood and adulthood. Hypotheses such as the fetal origins, developmental programming and predictive adaptive responses implicate deviations in fetal growth in causation of non-communicable diseases.

\section{What this study adds}

- Where associations were present, being small for gestational age was generally associated with adverse outcomes. There was evidence that both growth deceleration and acceleration were associated with adverse outcomes, and there were inconsistent associations between studies.

Contributors All authors were involved in conception and design. FA and AE undertook the searches. ST drafted the initial version of the manuscript and all authors contributed to revisions. ST is the guarantor of this work.

Competing interests None.
Provenance and peer review Not commissioned; externally peer reviewed.

\section{REFERENCES}

1 Susser M, Stein Z. Timing in prenatal nutrition: a reprise of the Dutch Famine Study. Nutr Rev 1994;52:84-94.

2 Lumey LH, Stein AD, Kahn HS, et al. Cohort profile: the Dutch Hunger Winter families study. Int J Epidemiol 2007;36:1196-204.

3 Stanner SA, Bulmer K, Andres C, et al. Does malnutrition in utero determine diabetes and coronary heart disease in adulthood? Results from the Leningrad siege study, a cross sectional study. Br Med J 1997;315:1342-8.

4 Gluckman PD, Hanson MA, Beedle AS. Early life events and their consequences for later disease: a life history and evolutionary perspective. Am J Hum Biol 2007:19:1-19.

5 Barker DJ. Fetal origins of coronary heart disease. BMJ 1995;311:171-4

6 Vaag AA, Grunnet LG, Arora GP, et al. The thrifty phenotype hypothesis revisited. Diabetologia 2012;55:2085-8.

7 Schlotz W, Phillips DI. Fetal origins of mental health: evidence and mechanisms. Brain Behav Immun 2009;23:905-16.

8 Ingelfinger JR, Schnaper HW. Renal endowment: developmental origins of adult disease. J Am Soc Nephrol 2005;16:2533-6.

9 Xita N, Tsatsoulis A. Review: fetal programming of polycystic ovary syndrome by androgen excess: evidence from experimental, clinical, and genetic association studies. J Clin Endocrinol Metab 2006;91:1660-6.

10 Hales CN, Barker DJ. Type 2 (non-insulin-dependent) diabetes mellitus: the thrifty phenotype hypothesis. Diabetologia 1992;35:595-601.

11 Hanson M, Godfrey KM, Lillycrop KA, et al. Developmental plasticity and developmental origins of non-communicable disease: theoretical considerations and epigenetic mechanisms. Prog Biophys Mol Biol 2011;106:272-80.

12 Gluckman PD, Hanson MA, Spencer HG. Predictive adaptive responses and human evolution. Trends Ecol Evol 2005;20:527-33.

13 Barouki R, Gluckman PD, Grandjean P, et al. Developmental origins of non-communicable disease: implications for research and public health. Environ Health 2012:11:42.

14 Geelhoed JJ, Steegers EA, van Osch-Gevers L, et al. Cardiac structures track during the first 2 years of life and are associated with fetal growth and hemodynamics: the Generation R Study. Am Heart J 2009;158:71-7.

15 Turner SW, Campbell D, Smith N, et al. Associations between fetal size, maternal alpha-tocopherol and childhood asthma. Thorax 2010;55:555-61.

16 Turner S, Prabhu N, Danielian P, et al. First and second trimester fetal size and asthma outcomes at age ten years. Am J Respir Crit Care Med 2011;184:407-13.

17 Sonnenschein-van der Voort AM, Jaddoe VW, Raat $\mathrm{H}$, et al. Fetal and infant growth and asthma symptoms in preschool children: the Generation R Study. Am J Respir Crit Care Med 2012;185:731-7.

18 Pike KC, Crozier SR, Lucas JS, et al. Patterns of fetal and infant growth are related to atopy and wheezing disorders at age 3 years. Thorax 2010;65:1099-106.

19 Parker M, Rifas-Shiman SL, Oken E, et al. Second trimester estimated fetal weight and fetal weight gain predict childhood obesity. J Pediatr 2012;161:864-70.

20 Ay L, Van Houten VA, Steegers EA, et al. Fetal and postnatal growth and body composition at 6 months of age. J Clin Endocrinol Metab 2009;94:2023-30.

21 Durmus B, Mook-Kanamori DO, Holzhauer S, et al. Growth in foetal life and infancy is associated with abdominal adiposity at the age of 2 years: the Generation R Study. Clin Endocrinol 2010;72:633-40.

22 Mook-Kanamori DO, Durmus B, Sovio U, et al. Fetal and infant growth and the risk of obesity during early childhood: the Generation R Study. Eur J Endocrinol 2011;165:623-30.

23 Whitehouse AJ, Zubrick SR, Blair E, et al. Fetal head circumference growth in children with specific language impairment. Arch Dis Child 2012;97:49-51.

24 van Batenburg-Eddes T, de Groot $L$, Steegers EA, et al. Fetal programming of infant neuromotor development: the Generation R Study. Pediatr Res 2010;67:132-7.

25 Henrichs J, Schenk JJ, Barendregt CS, et al. Fetal growth from mid- to late pregnancy is associated with infant development: the Generation R Study. Dev Med Child Neurol 2009;:52:644-51.

26 Hobbs K, Kennedy A, Dubray M, et al. A retrospective fetal ultrasound study of brain size in autism. Biol Psychiatry 2007;62:1048-55.

27 Whitehouse AJ, Hickey M, Stanley FJ, et al. Brief report: a preliminary study of fetal head circumference growth in autism spectrum disorder. J Autism Dev Disord 2011:41:122-9.

28 Abel KM, Dalman C, Svensson AC, et al. Deviance in fetal growth and risk of autism spectrum disorder. Am J Psychiatry 2013;170:391-8.

29 Visser AM, Jaddoe WW, Hofman A, et al. Fetal growth retardation and risk of febrile seizures. Pediatrics 2010;126:e919-25.

30 Blake KV, Gurrin LC, Beilin LJ, et al. Prenatal ultrasound biometry related to subsequent blood pressure in childhood. J Epidemiol Community Health 2002;56:713-18

31 van Houten VA, Steegers EA, Witteman JC, et al. Fetal and postnatal growth and blood pressure at the age of 2 years. The Generation R Study. J Hypertens 2009;27:1152-7 
32 Geelhoed JJ, Verburg BO, Nauta J, et al. Tracking and determinants of kidney size from fetal life until the age of 2 years: the Generation R Study. Am J Kidney Dis 2009;53:248-58.

33 Harvey NC, Mahon PA, Robinson SM, et al. Different indices of fetal growth predict bone size and volumetric density at 4 years of age. J Bone Miner Res 2010;25:920-7.

34 Harvey NC, Mahon PA, Kim M, et al. Intrauterine growth and postnatal skeletal development: findings from the Southampton Women's Survey. Paediatr Perinat Epidemiol 2012:26:34-44.

35 Ay L, Jaddoe WW, Hofman A, et al. Foetal and postnatal growth and bone mass at 6 months: the Generation R Study. Clin Endocrinol 2011;74:181-90.

36 Jaddoe VW, de Jonge LL, Hofman A, et al. First trimester fetal growth restriction and cardiovascular risk factors in school age children: population based cohort study. Br Med J 2014;348:g14.

37 Harvey NC, Cole ZA, Crozier SR, et al. Fetal and infant growth predict hip geometry at 6 y old: findings from the Southampton Women's Survey. Pediatr Res 2013;74:450-6.

38 Stick S. Pediatric origins of adult lung disease. 1. The contribution of airway development to paediatric and adult lung disease. Thorax 2000;55:587-94.
39 Saxen L. ed. Organogenesis of the kidney. New York: Cambridge University Press, 1987.

40 Turner SW, Devereux G. Fetal ultrasound: shedding light or casting shadows on the fetal origins of airway disease. Am J Respir Crit Care Med 2012;185:694-5.

41 Merialdi M, Carroli G, Villar J, et al. Nutritional interventions during pregnancy for the prevention or treatment of impaired fetal growth: an overview of randomized controlled trials. J Nutr 2003;133:1626S-31S.

42 Jaddoe VW, Mackenbach JP, Moll HA, et al. The Generation R Study: design and cohort profile. Eur J Epidemiol 2006;21:475-84.

43 Inskip HM, Godfrey KM, Robinson SM, et al. Cohort profile: the Southampton Women's Survey. Int J Epidemiol 2006;35:42-8.

44 Newnham JP, Evans SF, Michael CA, et al. Effects of frequent ultrasound during pregnancy: a randomised controlled trial. Lancet 1993;342:887-91.

45 Martindale S, McNeill G, Devereux G, et al. Antioxidant intake in pregnancy in relation to wheeze and eczema in the first two years of life. Am J Respir Crit Care Med 2005;171:121-8.

46 Gillman MW, Rich-Edwards JW, Rifas-Shiman SL, et al. Maternal age and other predictors of newborn blood pressure. J Pediatr 2004;144:240-5. 